\title{
Strategies for handling missing data in randomised trials
}

\author{
lan R White \\ From Clinical Trials Methodology Conference 2011 \\ Bristol, UK. 4-5 October 2011
}

Missing outcome data in randomised trials are a major potential source of bias in trial results, and their correct handling can be a major source of difficulty for investigators [1]. Missing outcome data matter for three main reasons:

1. They lead to a loss of power. This cannot be reversed, and so all efforts should be made to maximise completeness of follow-up.

2. Any analysis of incomplete data makes untestable assumptions and is likely to be biased if those assumptions do not hold. Because the correct assumption is usually unknown, it is important to justify the assumption used from subject-matter knowledge, and to perform sensitivity analyses.

3. Some popular analysis methods give inefficient estimates and/or biased standard errors, even if their assumptions are correct.

This talk will outline some of the statistical methods available for handling missing data in randomised trials, and what their underlying assumptions are. Some methods are simple to implement but harder to support: for example, "Last Observation Carried Forward" is based on an assumption that is rarely justified, while analysis of complete cases can be statistically inefficient. More complex methods such as mixed models and multiple imputation are usually based around a missing at random assumption, which is popular because it is perceived to become more plausible as models become more complex.

The intention-to-treat principle is sometimes seen as requiring missing values to be imputed. By focussing instead on assumptions, I will show that it is sufficient for all observed data to be included in the main analysis, but that sensitivity analyses must take account of all

Correspondence: ian.white@mrc-bsu.cam.ac.uk

MRC Biostatistics Unit, Cambridge CB2 OSR, UK randomised individuals. This approach will be summarised in an intention-to-treat analysis strategy [2].

I will also briefly describe how to perform a sensitivity analysis and how to handle missing baseline variables.

Published: 13 December 2011

\section{References}

1. National Research Council: The prevention and treatment of missing data in clinical trials. The National Academies Press; Washington, DC; 2010

[http://www.nap.edu/catalog.php?record_id=12955].

2. White IR, Horton N, Carpenter J, Pocock SJ: Strategy for intention to treat analysis in randomised trials with missing outcome data. British Medical Journal 2011, 342:d40[http://www.bmj.com/content/342/bmj.d40].

doi:10.1186/1745-6215-12-S1-A59

Cite this article as: White: Strategies for handling missing data in randomised trials. Trials 2011 12(Suppl 1):A59.

Submit your next manuscript to BioMed Central and take full advantage of:

- Convenient online submission

- Thorough peer review

- No space constraints or color figure charges

- Immediate publication on acceptance

- Inclusion in PubMed, CAS, Scopus and Google Scholar

- Research which is freely available for redistribution

Submit your manuscript at www.biomedcentral.com/submit
() Biomed Central 